\title{
Uma visão geral da IX Semana da Cultura Religiosa pelo olhar de alguns alunos
}

Eva Aparecida Rezende de Moraes ${ }^{1}$

Em setembro de 2017, a Cultura Religiosa realizou a sua 9a edição da SEMANA DA CRE. Nos inícios da preparação, a Equipe Organizadora ficou apreensiva, devido ao tema, que era óbvio: comemoração dos 300 anos da aparição da imagem de Nossa Senhora Aparecida nas águas do rio Paraíba do Sul. A angústia inicial não era quanto ao tema, mas quanto à acolhida do mesmo pelos nossos alunos que possuem outra denominação religiosa. Não seria um tema "muito católico"? Como seria a reação dos alunos? Mas a resposta deles foi surpreendente! É o que procurarei partilhar neste texto, a partir das colocações de alguns de meus alunos daquele período.

A IX Semana ficou distribuída em três "eixos": na terça-feira (26/09), o do diálogo com as outras religiões - eixo trabalhado pela disciplina "O Humano e o Fenômeno Religioso". Na quarta-feira (27/09), o "eixo" foi a reflexão sobre Maria para nossa realidade católica conteúdo trabalhado pela disciplina "O Cristianismo"; e, na quinta-feira (28/09), o "eixo" foi a ética que o tema mariano implica e/ou suscita - conteúdo das disciplinas de "Ética Cristã" e "Ética Socioambiental e Direitos Humanos".

No dia 26 de setembro, uma terça-feira, os trabalhos da mesa das $9 \mathrm{~h}$ às $11 \mathrm{~h}$ tiveram como tema "Os traços da devoção Mariana na cultura brasileira", apresentado pela professora de Ciências Sociais pela UERJ Cecilia Loreto Mariz e pelo Monsenhor Pe. José Roberto Rodrigues Devellard, professor da nossa Cultura Religiosa. Usaremos, aqui, o parecer da aluna Fernanda $M$; segundo o seu relatório, a professora Cecília começou a palestra destacando como a imagem de Maria é vista por todos no Brasil: 'Mãe de Misericórdia'; a professora citou as diversas aparições de Maria na América Latina - como a de Nossa Senhora de Guadalupe, no México e a de Nossa Senhora da Caridade do Cobre, em Cuba. Segundo a palestrante, muitas dessas aparições surgem para pessoas das classes menos abastadas e não ligadas à produção do sagrado. O segundo palestrante dedicou seu tempo para falar das diferentes manifestações de arte sacra ao redor do mundo e como essa arte honra a imagem de Maria; segundo ele, a arte sacra foi implantada no Brasil-Colônia e tomou um caráter bastante genérico na época. Destacou que, através da arte sacra, é possível se fazer uma meditação e uma oração, uma elevação da alma e discursou sobre os ícones, os mosaicos e as pinturas murais da Virgem Maria. Citou também outras marcas da devoção a Maria, como: a coroação de Nossa Senhora no final do mês de maio, as procissões com as faces de Maria, festas católicas marianas (como a "apresentação de Nossa Senhora" e a "Festa da Purificação"). Lembrou que a oração do terço é a devoção a Maria mais presente e praticada, ressaltando que Maria representa o ideal feminino de virtude em toda a humanidade: encontram-se mais de

\footnotetext{
${ }^{1}$ Teóloga, professora do Departamento de Teologia da PUC-Rio, setor de Cultura Religiosa.
} 
mil nomes de Nossa Senhora na internet - é o nome pessoal feminino mais frequente no mundo ocidental. Lembrou que existem outras manifestações da devoção mariana, como a construção de igrejas em sua homenagem (como a Notre Dame em Paris e Santa Maria Maggiore em Roma); diversos poemas (como os de Paul Claudel e Jorge de Lima); filmes e peças (como "O Auto da Compadecida"); músicas cantadas por cantores famosos (como Roberto Carlos, Erasmo Carlos, Maria Betânia, Elis Regina e Elba Ramalho).

O tema da mesa das $11 \mathrm{~h}$ às $13 \mathrm{~h}$ foi "Os 300 anos da aparição de Nossa Senhora em Aparecida". Quem vai nos ajudar a dar uma visão geral sobre as palestras será o aluno Gabriel J. O primeiro palestrante foi o professor de direito da PUC-Rio, Dante Limongi; ele abordou e aprofundou o tema da reforma trabalhista e uma maior flexibilização em relação à terceirização. Apresentou pontos positivos e negativos em relação à atual reforma trabalhista do governo Michel Temer, destacando que pontos dessa discussão já foram apresentados no século XIX; o professor trouxe dados sobre o desemprego em outros países, analisou a importância da relação das leis trabalhistas com o empregado e como elas favorecem o trabalhador no Brasil. Logo após, o professor ligou tudo isso à religião: citou os Franciscanos, Jesuítas e outros grupos religiosos no Brasil que se posicionaram em relação ao tema dos direitos do trabalhador; destacou que os religiosos veem o trabalho como uma atividade que enobrece o ser humano e o aproxima de Deus. A partir dessa palestra, o aluno acima referido disse ter entendido um pouco mais sobre a visão e a função social importante que a religião tem na sociedade atual. $O$ segundo palestrante foi 0 economista e professor de Relações Internacionais e da Cultura Religiosa da PUC-Rio, João Antônio Sucupira. Ele baseou a palestra na atual reforma trabalhista, contou um pouco do contexto das empresas BNDES e Petrobras, mostrando como o potencial do nosso país é desperdiçado em casos de propinas e corrupção.

O tema das $13 \mathrm{~h}$ às $15 \mathrm{~h}$ foi "O Sagrado feminino nas religiões de matriz africana". A aluna Beatriz M. M. compartilhou em um relatório o que captou nesta palestra. Segundo ela, a candomblecista e professora de história Monica Baptista Costa nos propôs pensar como as religiões africanas enxergam a mulher - que possui um papel de destaque nesta religião -, pensando no ponto de vista sociocultural. A palestrante ressaltou que, diferente do cristianismo, o candomblé é de origem mitológica: para essa religião, os mitos exercem um importante papel. Os mitos mais importantes são os da criação do mundo e da humanidade, nos quais há a presença do sagrado feminino. Por sua vez, a segunda palestrante a ocupar a mesa, a professora e pesquisadora da história de populações indígenas e negras, Denise Pini $R$. da Fonseca, historiadora e professora do Serviço Social da PUC-Rio, nos informou que, ao entrar em contato com indígenas e outras populações de minorias ao redor do mundo e resistentes na história, ela descobriu várias documentações e registros de mulheres; ela afirmou que é importante observar outras formas de saber além da acadêmica e nos convidou 
a ler mais a respeito das matrizes africanas. Ela destacou cinco grandes mulheres nas religiões africanas: Nana, Yemojá, Oxum, Oya e Obà - e contou suas mais diversas qualidades.

O dia 27/09, quarta-feira, foi o do eixo do "Cristianismo". No horário das $15 \mathrm{~h}$ às $17 \mathrm{~h}$, esteve presente o aluno Breno $S$. S., que vai nos relatar o que sentiu do trabalho dessa mesa o tema foi "Maria na tela de cinema e no coração do povo latino-americano". Segundo seu relatório, a atividade começou com uma música do Chico Buarque referente a Maria e o público presente a acompanhou cantando. Logo após a professora de teologia da PUC-Rio, Tereza Cavalcanti mostrou, em slides, as diferentes versões de Maria, advindas dos países latinos, e falou rapidamente da história de cada uma, se aprofundando na padroeira da América Latina Nossa Senhora de Guadalupe. Ela explicou o que significam os versos da oração da 'Ave Maria', falou um pouco da história de Nossa Senhora e esclareceu que nós, católicos, não 'adoramos' a Maria, mas a veneramos. Tereza falou sobre a importância da presença de Maria no primeiro milagre de Jesus ('Bodas de Caná') e lembrou que Maria é mulher que não se cala, mulher da denúncia. O segundo palestrante foi o pastor batista e teólogo Alessandro Rocha e ele falou de Maria retratada na tela de cinema. Citou alguns filmes - em especial, o "Marias - A fé no feminino", um documentário que aborda o feminino na América Latina, passando por algumas festas da padroeira de países como Brasil, Cuba, México e alguns outros. Ele explicou bastante o sagrado feminino e, ao final, abriu para perguntas. $O$ aluno disse perceber $\mathrm{e}$ entender agora o amor que muitos latinos têm por Nossa Senhora, como isso influencia os países e como existe uma quantidade enorme de seguidores de padroeiras pela América Latina.

No dia 28/09, quinta-feira, último dia dos trabalhos, o eixo foi "Ética". De $7 \mathrm{~h}$ às $9 \mathrm{~h}$, abrindo o dia, o tema foi "O 'Magnificat' e os milagres de Aparecida". O aluno Breno S. S. nos ajuda a relatar o que aconteceu: a atividade começou com uma música de ambientação; em seguida, o professor da Cultura Religiosa Alexandre Chaves passou um vídeo narrando como foi achada a imagem de Nossa Senhora Aparecida, que ainda se encontra na Basílica de Nossa Senhora Aparecida, em São Paulo. Após uma breve conversa sobre esse vídeo, o professor Roberto Teixeira da Cultura Religiosa apresentou o 'Cântico do Magnificat' e seu significado (encontrado no Evangelho de Lucas). O aluno, no seu relatório, reflete sobre os milagres de Nossa Senhora Aparecida: eles são brasileiros, mas parecem 'passagens bíblicas' devido ao amor de vários brasileiros a Nossa Senhora! Ele vê o exemplo de sua mãe, que é devota de Nossa Senhora Aparecida, todo o carinho que sua mãe tem para com ela, como também sua avó; seu pai faleceu quando ele tinha 5 anos, ele foi criado pelas duas e sempre viu as duas com esse carinho enorme com Nossa Senhora! Ele diz em seu relatório que, 'se é possível dizer, ela me criou também'!

O tema da mesa de $11 \mathrm{~h}$ às $13 \mathrm{~h}$ foi "Ética e Direitos Humanos: para enfrentar as diversas formas de escravidão contemporâneas" e quem nos ajuda a relatar é a aluna Camila B. K. A primeira palestrante, Regina Novaes, abordou a questão através da perspectiva dos 
jovens; segundo ela, toda experiência de juventude é 'inédita' - neste sentido, existem 'juventudes', no plural. Nesta perspectiva, destacou três momentos históricos: no tempo da 'moratória social', quando se acreditava que os jovens estudantes deveriam somente se preparar para o ingresso no mercado profissional e não realizavam a formação social; no tempo da crise do modelo de desenvolvimento, surge a categoria dos "jovens em situação de risco", uma segunda categoria de preocupação; num terceiro e atual momento, os jovens são entendidos como "sujeitos de direitos", que se preocupam com o exercício de direitos sociais. Em seguida, a palestrante analisa os direitos trabalhistas da atual juventude, mencionando as marcas da desigualdade e a presença da imprevisibilidade e da competitividade ligadas à condição juvenil e as diferenças de cor, etnia, gênero, orientação sexual, que retroalimentam as desigualdades sociais. Ao lado de tais recortes, a religião também é um aspecto relacionado à composição do "mosaico" da grande diversidade da juventude brasileira: no Brasil, com o decorrer do tempo, cresceu a categoria de jovens que afirmam sua fé em Deus, mas não a crença em uma religião - nesse sentido, pergunta-se sobre a existência de uma crise na religião dos jovens. Segundo a palestrante, uma grande característica da atuação religiosa dos jovens é a mistura de identidades formando um forte sincretismo religioso e, também, conectando a religião às demais questões da sociedade.

A segunda palestrante, professora Thula Rafaella Pires, iniciou sua fala partindo da questão do descompasso entre país legal e real; fala da reprodução de práticas excludentes institucionalizadas, colocadas por ela como "zonas do não ser". Nos lembrou que é preciso enfrentar as desigualdades, que são herança de outros tempos; a atuação em conjunto é necessária para expandir um movimento de forma coletiva, a instaurar um novo sentido que não implique na perda de direitos nem na existência de privilégios. No momento religioso, deve existir maior compromisso por parte do coletivo, com a extinção das práticas intolerantes e violentas. Para a aluna, a aproximação do jovem com o Sagrado, independentemente do formato em que se estabelece, é elemento de grande importância na sua formação, pois irá estabelecer ou reforçar seus pilares éticos, oferecendo, à sua maneira, uma educação social; trata-se, também, de exercício do autoconhecimento, a partir do momento em que esse jovem passa a ter maior compreensão sobre aspectos de grande abstração de sua vida, bem como da existência. A religião, portanto, tem o papel de oferecer uma saída ao jovem. 0 reconhecimento das desigualdades, herdadas socialmente pela juventude, deve ser aliado ao movimento no sentido de extingui-las e esse papel cabe também à religião.

Na palestra das $13 \mathrm{~h}$ às $15 \mathrm{~h}$, o tema foi "Ética, Direitos Humanos e as 'Marias' de nosso tempo". A mesa foi dividida entre duas mulheres e quem vai nos ajudar a ter uma leitura rápida desse trabalho é o aluno Pedro M. Segundo seu relatório, a jornalista Karla Maria iniciou a palestra fazendo um breve histórico de sua carreira jornalística, contando que, por conta da sua profissão, tem contato com pessoas em situação de fragilidade social; cobrindo matérias com mulheres negras e indígenas, ela constatou o preconceito social, racial e de gênero. Fez, por 
exemplo, uma matéria na 'cracolândia' de São Paulo, onde buscou retratar o dia-a-dia das pessoas de lá e viu de perto o terror dos locais onde essas pessoas vivem. Esses e outros casos se encontram no livro de sua autoria "Mulheres Extraordinárias".

A segunda palestrante, professora Eliana Yunes, o aluno achou excelente: relatou que foram momentos de muita reflexão. Ela nos lembrou que muitas pessoas vivem entre nós, mas suas dores são invisíveis; definiu o significado da palavra 'ordinário', pontuando em seguida que o 'extraordinário' encontra-se em nossa condição humana - ou seja: somos, então, 'extraordinários' ao sermos mais humanos em todas as nossas relações sociais, buscando sempre a justiça e o bem do próximo. Também o aluno João Antônio F. C. N. destacou a última palestra; ele nos lembrou, em seu relatório, o que a professora discerniu: que Maria, mãe de Deus, foi um exemplo de mulher digna e perfeita, mas, na verdade, sofreria preconceito por ter aparecido grávida sendo virgem - ou seja, nem mesmo a sagrada família escapou dos julgamentos da sociedade! Ele destacou que, hoje, as mulheres têm mais espaço em nossa sociedade graças à brava luta que travaram em busca de seus direitos naturais, mas que há, ainda, muita desigualdade entre os gêneros masculino e feminino e entre mulheres negras e brancas. A palestrante finalizou, contando um pouco do que entende por 'felicidade', mostrando que 'amor' é um sentimento que necessita da reciprocidade. Pediu que refletíssemos como poderíamos melhorar nossas atitudes, buscando que o outro se sinta melhor; comentou que essa mudança não acontece de imediato e que, quando esse comportamento for um hábito, passaremos a tratar a todos de forma mais amorosa, nos aproximando do 'extraordinário' que é ser humano!

No encerramento da IX Semana da CRE, a cerimônia teve como título "Memórias de Mulheres da PUC-Rio", visando recordar algumas grandes mulheres que marcaram a vida da nossa Comunidade acadêmica. Para relatar esse momento, partilhamos as impressões da aluna Gabriela P. S. C. Com a participação dos professores da Cultura Religiosa Marivani de Aquino Pereira e Alexandre Chaves, a cerimônia se iniciou com a descrição de Maria nos evangelhos; também foi dado um grande destaque ao canto mariano 'Magníficat'; se enfatizou, em Maria, as dimensões do cuidado (mãe que ensina e cuida do filho), do serviço (tinha pressa em ajudar as pessoas), da fidelidade (seguidora de Jesus, esteve com ele até o final) e da persistência (após a morte do seu filho, tornou-se a mãe da comunidade de seus seguidores). Maria foi lembrada com o rosto negro de Nossa Senhora Aparecida, responsável por vários milagres acontecidos no cotidiano simples de pessoas simples. A segunda parte da cerimônia trouxe exemplos de mulheres que incorporam a essência do canto mariano do 'Magníficat': as 'Marias da PUC-Rio'. A primeira citada foi a professora da Cultura Religiosa Maria Regina, uma mulher cuja vida foi dedicada intensamente à docência e que enfrentou um câncer de pele sem abandonar a sala de aula; Lélia Gonzalez foi uma ativista política e pesquisadora da cultura negra; outra lembrada foi a professora Ana Waleska, que esteve presente em diversas passeatas contra a ditadura e de movimento estudantil; Dona Joana - uma faxineira da PUC- 
Rio - criou muitos filhos não biológicos com o simples intuito de ajudar ao próximo. Por fim, foi exposto um pouco da pessoa e da vida de Dom Hélder Câmara, um verdadeiro devoto de Maria Aparecida.

Enfim, concluo com as observações da aluna Camila B. K.: para ela, a figura de Maria é emblemática - não apenas para uma determinada crença religiosa, mas por ser elemento de presença constante nas mais diversas culturas. Ela acredita que a imagem mariana - com representações das mais diversas - é elemento cultural de grande importância pela força de sua mensagem. A figura de Maria é representação de uma ética universal, de um pensamento a ser reproduzido. 